\title{
Modelo Geoespacial para a Identificação de Áreas com Perigo de Propagação de Queimadas no Parque Nacional da Serra da Canastra
}

\author{
Geospacial Model for Identification of Areas With Fire Propagation Danger \\ in the Serra da Canastra National Park, Brazil
}

\author{
Cassiano Gustavo Messias* $\bowtie$ (iD, Marcos César Ferreira $\bowtie$ (iD) \\ Departamento de Geografia, Instituto de Geociências, Universidade Estadual de Campinas - \\ Capinas, São Paulo, Brasil. E-mail: macferre@unicamp.br (MCF). \\ *E-mail para correspondência: cassianomessiaslavras@gmail.com (CGM).
}

Recebido (Received): 10/01/2019

Aceito (Accepted): 25/03/2019

\begin{abstract}
Resumo: Apesar do fogo ser parte da dinâmica e evolução do Cerrado, queimadas de forma indiscriminada são um problema para a longevidade de Unidades de Conservação (UC). O Parque Nacional da Serra da Canastra (PNSC), localizado a Sudoeste do estado de Minas Gerais, Brasil, tem o fogo como uma das principais atividades conflitantes. Este trabalho tem como objetivo criar uma metodologia para a geração de um modelo de perigo potencial de propagação de queimadas, aplicado no PNSC. Para isto, foram mapeadas variáveis geoambientais associadas à propagação do fogo, sendo elas: hipsometria, declividade, efeito do vento nas encostas, índice de convexidade das vertentes, índice de vegetação, densidade de drenagem e densidade de vias. A dependência espacial entre as áreas de alta recorrência de queimadas e estas variáveis geoambientais foi avaliada pelo teste Kolmogorov-Smirnov, que foi também utilizado para atribuir pesos às variáveis. A modelagem foi realizada em Sistemas de Informações Geográficas (SIG) e empregou mapas probabilísticos Fuzzy. Os resultados mostraram que o Chapadão da Canastra e o Chapadão da Babilônia apresentam perigo de propagação elevado. O perigo de propagação nas depressões intermontanas é médio, e na zona de amortecimento, o perigo é baixo. O modelo foi validado, o que comprovou a eficiência desta metodologia.
\end{abstract}

Palavras-chave: Incêndios florestais; Unidade de Conservação; Mapeamento de Risco; Teste KolmogorovSmirnov.

Abstract: Despite the fire being part of the dynamics and evolution of the Brazilian Savanna (Cerrado), indiscriminate forest fires are a problem for Conservation Units longevity. The Serra da Canastra National Park (SCNP) is located in southwest of Minas Gerais, Brazil, and it has the fire as one of the main conflicting activity. This work had as aim to create a methodology for the generation of a potential danger model for fire propagation, which was applied in the SCNP. For that, geo-environmental variables associated with fire propagation were mapped: hypsometry, slope, wind surface effect, surface convexity index, vegetation index, drainage density and roads density. The spatial dependence among the areas of high fire recurrence and these geo-environmental variables was evaluated by Kolmogorov-Smirnov test, with weights associated with the variables. The modeling was generated in Geographic Information System (GIS) and employed Fuzzy probabilistic maps. The results showed that the Chapadão da Canastra and the Chapadão da Babilonia present a high potential danger of fire propagation. The danger of propagation in the flat plain between mountain slopes is medium, and in the buffer zone is lower. The model was validated, proving the method efficiency.

Keywords: Forest fires; Parks; Risk mapping; Kolmogorov-Smirnov Test. 


\section{Introdução}

O fogo influencia fortemente as populações e as comunidades de plantas em todo o mundo, funcionando como um agente de alteração da vegetação através de múltiplos caminhos, tanto acima, como abaixo do solo (GAGNON et al., 2015). Os ecossistemas do Cerrado dependem do regime histórico do fogo para manter sua estrutura, biodiversidade e funcionamento (DURIGAN; RATTER, 2016). Por exemplo, as queimadas promovem a rebrota de várias espécies do extrato herbáceo e agem como estimulantes da floração (CONTI; FURLAN, 2011).

Por outro lado, os benefícios das queimadas não são extensivos a todas as formações vegetais. O fogo pode promover danos à diversidade de espécies, havendo a possibilidade de desaparecimento de algumas; pode causar alterações na biomassa vegetal; as funções biológicas podem ser afetadas pelo aumento das espécies dominantes; os solos podem também ser afetados, através da redução da porosidade e da infiltração de água (COSTA-MILANEZ ET al., 2015). O fogo pode também mediar a invasão de espécies exóticas (STEVENS; BECKEGE, 2009).

Deste modo, estudos mostram que tanto a frequente, como a rara ocorrência do fogo, pode afetar a conservação e a biodiversidade no Cerrado (DURIGAN; RATTER, 2016). A supressão excessiva pode levar ao aumento da carga de combustível (especialmente de combustível morto), ocasionando incêndios futuros mais intensos e severos, o que pode também ameaçar a biodiversidade (RISSI et al., 2017). Por isto, as áreas de Cerrado requerem uma política de gerenciamento do fogo clara (DURIGAN; RATTER, 2016). Contudo, os impactos nos processos ecológicos, culturais e econômicos permanecem ainda pouco compreendidos, dificultando a criação de planos de ação efetivos para prevenção, controle ou gestão de incêndios (GOMES et al. 2018).

Embora o controle do fogo seja difícil, os modelos que estimam o perigo de incêndio auxiliam na prevenção dos impactos negativos causados (ESKANDARI; CHUVIECO, 2015), e na redução do número de ocorrências e da área atingida (POLDONI et al., 2017). Os Sistemas de Informações Geográficas (SIG) e os produtos de sensoriamento remoto são ferramentas eficientes na avaliação do perigo de incêndios. Aliando o uso do SIG a conhecimentos sobre a distribuição espacial e temporal de condições prévias ao fogo, como as características do terreno, a quantidade de combustível e as condições do clima, pode-se obter uma melhor compreensão da ocorrência deste fenômeno espacial (ALLGÖWER et al., 2003; CHUVIECO et al., 2010; CARVALHO et al., 2017).

O fogo é considerado, na região da Serra da Canastra, como um dos principais elementos indutores de alteração da paisagem, e maior parte tem origem antrópica (MMA; IBAMA, 2005). Os incêndios ocorrem, principalmente, durante a estação seca, com maior frequência entre junho e outubro. Nesta época, normalmente os focos ativos encontram condições propícias para se desenvolverem em grande magnitude (MAGALHÃES et al., 2012). O fogo tem causado impactos na biodiversidade do PNSC, como a morte dos indivíduos da fauna terrestre e semiaquática. Devido à sua ocorrência, especialmente quando relacionado ao manejo das pastagens, as formações florestais existentes sofreram, em graus diferentes, algum tipo de alteração (MMA; IBAMA, 2005).

Este artigo tem como objetivo geral desenvolver um modelo de perigo de propagação de queimadas, aplicado no Parque Nacional da Serra da Canastra (PNSC) e em sua zona de amortecimento (ZA). Para atingir este objetivo, os procedimentos metodológicos apresentados por Taylor (1977) foram adaptados à aplicação de ferramentas de modelagem em SIG, possibilitando atribuir pesos para variáveis geoambientais associadas com a propagação de queimadas, através do teste Kolmogorov-Smirnov (KS). Foi também utilizado o processo classificatório Fuzzy, com o intuito de gerar um mapa probabilístico de perigo.

\section{2. Área de Estudo}

O PNSC está localizado a sudoeste do estado de Minas Gerais, Brasil, inserindo-se em onze municípios mineiros. Foi criado pelo decreto $\mathrm{n}^{\circ} 70.355$, de 3 de abril de 1972, sendo estabelecida uma área de 197.787ha, mas, naquele momento, apenas 71.525ha do Chapadão da Canastra foram regularizados. Atualmente, em torno de 82.000 ha são regularizados, abrangendo o Chapadão da Canastra e também polígonos dispersos pelo Chapadão da Babilônia (Figura 1).

Esta Unidade de Conservação (UC) está inserida no domínio do Cerrado, e o clima corresponde ao tipo Cwb de Köppen, com verão chuvoso e inverno seco. A pluviosidade pode variar entre 1.000 e $1.500 \mathrm{~mm} /$ ano. O PNSC abrange as bacias hidrográficas dos rios São Francisco, Grande e Paranaíba, e nele estão localizadas a nascente histórica do rio São Francisco e a geográfica do rio Araguari. De modo geral, o interior do parque é formado pelos grandes blocos de Chapadões quartzíticos da Canastra e da Babilônia, zonas mais elevadas, 
que podem atingir até $1.500 \mathrm{~m}$. Os Chapadões estão emoldurados por zonas rebaixadas, formadas por rochas menos resistentes que o quartzito, que podem variar entre 600 e 1.100m (MMA; IBAMA, 2005).

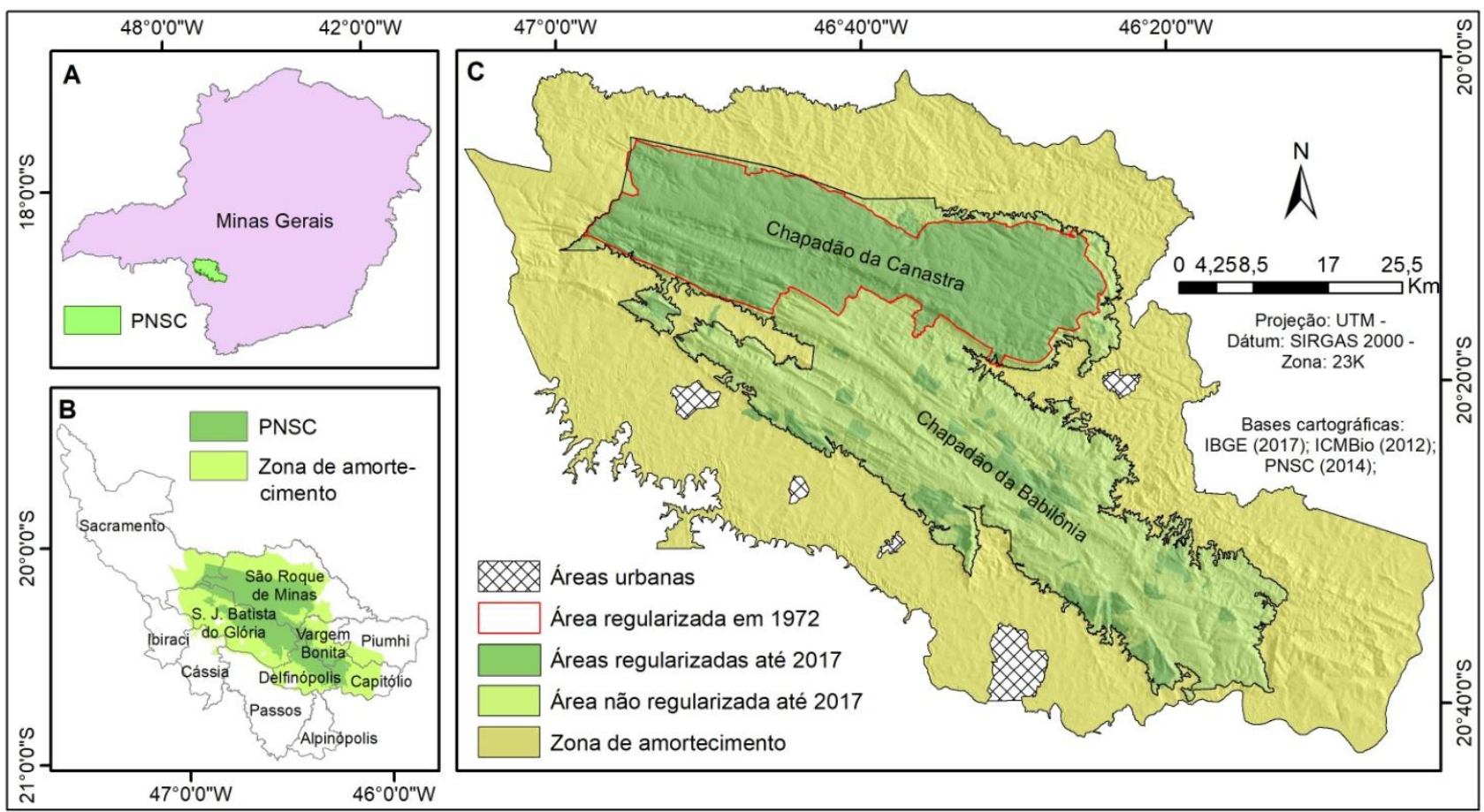

Figura 1: Mapa de localização do PNSC e sua ZA em escala

\section{Material e Métodos}

\subsection{Mapeamento de Variáveis Geoambientais Associadas à Propagação de Queimadas}

Esta etapa da pesquisa tem como objetivo cartografar elementos da paisagem que, possivelmente, estão associados à propagação de queimadas no PNSC. As variáveis geoambientais selecionadas, a justificativa da escolha e o material e métodos adotados estão descritos no Quadro 1. O mapa de cada variável teve intervalos de classes atribuídos pela técnica quantil, em oito classes, que foram distribuídas com áreas semelhantes (FERREIRA, 2014).

Quadro 1: Informações referentes à escolha e à geração de mapas das variáveis geoambientais.

\section{Variável}

Índice de vegetação da diferença normalizada (NDVI)

Hipsometria $\mathrm{O}$ teor de umidade atmosférica diminui exponencialmente com o aumento da altitude (BÖHER; ANTONIC, 2009). Em altitudes elevadas são comuns fitofisionomias de menor porte e que são combustíveis no período seco (TORRES, 2006). O aumento da altitude tende a elevar o perigo de propagação.

\section{Material e métodos}

Foram selecionadas 22 imagens Landsat TM, ETM+ e OLI, do início do período seco e de anos diferentes, em um período que varia entre 1984 e 2015, para cada cena que abrange o PNSC (órbita/ponto 219/74 e 220/74). Foi realizada a correção atmosférica destas imagens, pelo módulo Fast Line-of-sight Atmospheric Analysis of Spectral Hypercubes (FLAASH), do ENVI 4.2. Pela ferramenta Cell statistics, do ArcGIS 10.2, realizou-se uma álgebra das 22 imagens de cada cena. Aplicou-se a mediana como medida de tendência central da reflectância, obtendo uma imagem única.

O NDVI foi obtido através da diferença da reflectância no infravermelho próximo (IVP) e no vermelho (VER), dividida pela soma da reflectância no IVP e no VER.

O modelo digital de elevação (MDE) ASTER GDEM, versão 2 (2011), foi utilizado na geração do mapa hipsométrico.

Este mapa foi produzido a partir do agrupamento dos valores de elevação do MDE citado em classes altimétricas, através do ArcGIS 10.2. 
significativamente na taxa de propagação do fogo. As encostas mais íngremes são mais suscetíveis à propagação (AJIN et al., 2016). Convexida- Nas formas côncavas ocorre a convergência de da de fluxos hídricos, sendo áreas mais úmidas, superfície de onde a vegetação tende a ter maior terreno densidade. Por outro lado, as feições convexas são dispersoras de fluxos, e tendem a ser mais secas, isto é, supostamente mais susceptíveis aos incêndios (COURA et al., 2009).

Efeito do Os ventos alimentam a combustão e vento nas direcionam os incêndios, facilitando, vertentes portanto, sua propagação (TORRES, 2006). Deste modo, áreas que recebem diretamente o vento predominante, são mais propícias à propagação de queimadas.

\section{Densidade de vias de circulação}

Densidade
de
drenagem

Densidade drenagem
As estradas podem limitar a área queimada e atuam como barreiras espaciais à propagação o fogo, devido à redução de combustível. Além disto, as estradas também dão acesso aos locais em que há focos existentes, para a supressão dos mesmos (CUI; PERERA, 2008). Locais de menor densidade de vias são, supostamente, mais susceptíveis à propagação do fogo.

Os corpos d'água atuam como barreiras espaciais à propagação do fogo (CUI; PERERA, 2008). Ademais, estão comumente associados a fitofisionomias de maior biomassa vegetal, como as matas, que reduzem a velocidade de propagação (MMA; IBAMA, 2005).
Slope, no ArcGIS 10.2. Como raster de entrada foi utilizado o modelo ASTER GDEM 2, e o produto foi obtido em graus.

Os índices de convexidade da superfície do terreno foram calculados no SAGA GIS 6, pelo módulo Terrain Surface Convexity (IWAHASHI; RICHARD, 2007). O modelo ASTER GDEM 2 foi utilizado como raster de entrada.

No mapa gerado, quanto maior o valor do pixel, maior concentração de superfícies convexas.

O aplicativo Wind effect, do SAGA GIS 6, possibilitou gerar o mapa de efeito do vento. Utilizou-se o ASTER GDEM 2, e o azimute $120^{\circ}$ como direção predominante do vento (MMA; IBAMA, 2005).

No produto obtido, valores menores que 1,0 representam áreas que não recebem o vento predominante e, maiores que 1,0 , que o recebem diretamente.

Foram extraídas imagens em alta resolução do Google Earth Pro, as quais foram registradas e mosaicadas no ArcGIS 10.2. Estas imagens serviram como base para a digitalização das estradas não pavimentadas e das rodovias, contidas na área de estudo.

O mapa de densidade de vias foi criado pela ferramenta Kernel Density, utilizando o raio de $3 \mathrm{~km}$.

A drenagem da área de estudo foi extraída do modelo ASTER GDEM 2, através da execução de funções do Hydrology, contido no ArcGIS 10.2.

O mapa de densidade de drenagem foi gerado pela ferramenta Kernel Density, utilizando o raio de $3 \mathrm{~km}$.

\subsection{Definição do n da Amostra}

Antes de iniciar os procedimentos de aplicação do teste $K S$, é necessário definir uma amostra empírica, que será utilizada no cruzamento. Messias e Ferreira (2017) mapearam as queimadas no PNSC entre 1984 e 2015, e geraram um mapa de recorrência de queimadas, que mostra a frequência dos eventos neste intervalo de tempo, e nos diferentes ambientes do parque. Este mapa foi apresentado originalmente em escala Fuzzy, sendo assim, os limites entre as classes foram representados por zonas transitórias, e os valores de recorrência foram distribuídos de forma contínua em valores reais no intervalo [0,1] (FERREIRA, 2014).

Neste artigo, o mapa citado teve intervalos de classes atribuídos por desvio padrão, método que possibilita eliminar a interferência subjetiva do pesquisador (FERREIRA, 2014) (Figura 2A). A classe de recorrência

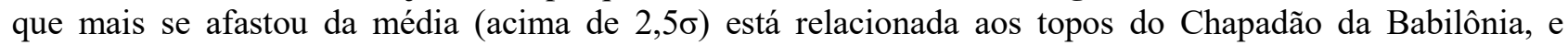
também a pequenos trechos a centro-oeste da ZA. Estas áreas, que concentram as maiores incidências de queimadas no PNSC no período citado, serão consideradas críticas de recorrência de queimadas.

Para definir o valor $n$ da amostra para o teste $K S$, foi gerada uma amostra sistemática de pontos sobre as áreas críticas de recorrência de queimadas, em uma malha regular de 500m x 500m. Deste modo, foi gerado um ponto amostral a cada $0,25 \mathrm{~km}^{2}$, e o $n$ da amostra é o número total de pontos, ou seja, $n=664$ (Figura 2B). 


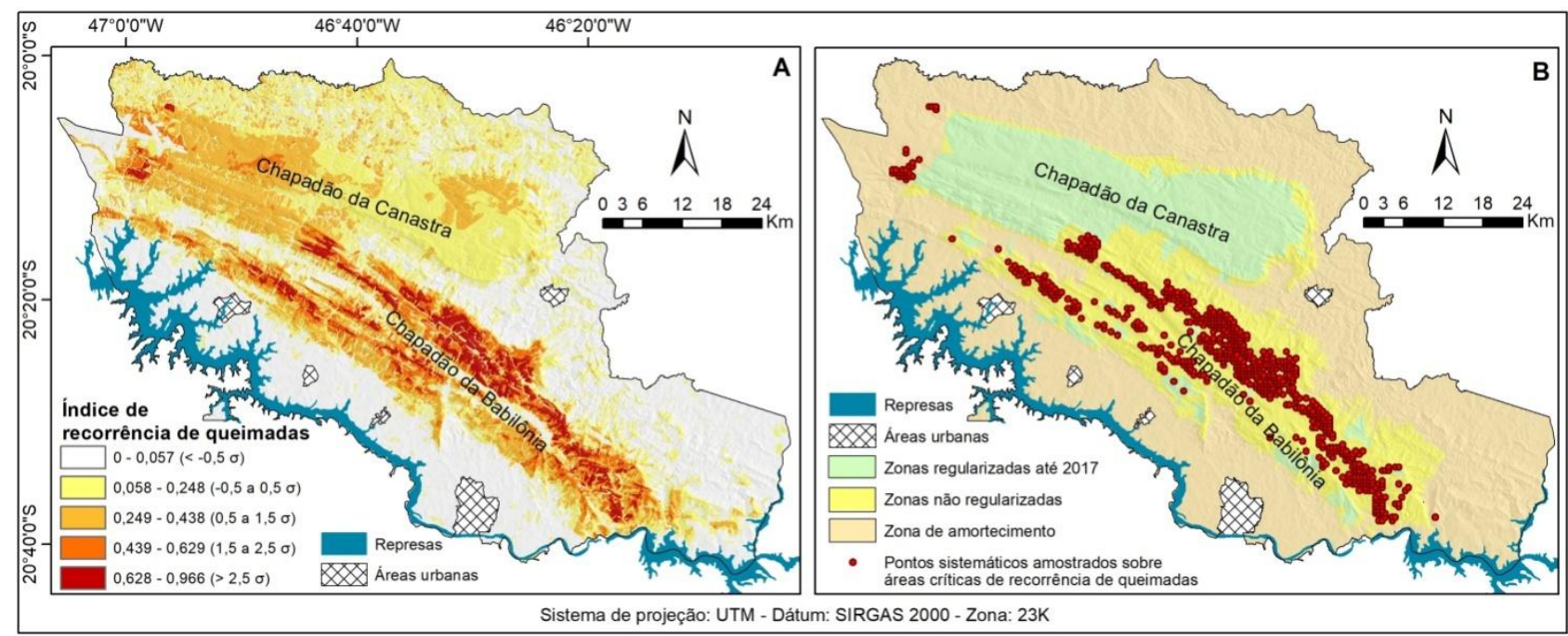

Figura 2: Índice de recorrência de queimadas (A) e pontos amostrados sobre áreas críticas de recorrência de queimadas no Parque Nacional da Serra da Canastra (B).

\subsection{Modelagem do Perigo de Propagação de Queimadas}

A metodologia proposta neste artigo utiliza o teste $K S$ para avaliar a aderência entre pontos amostrais, distribuídos sobre as áreas críticas de recorrência de queimadas, e as variáveis geoambientais possivelmente associadas à propagação de queimadas no PNSC. O KS é um teste não paramétrico, que pode ser utilizado para testar a normalidade de dados (TAYLOR, 1977), comparando uma função de distribuição cumulativa empírica $\left(H_{l}\right)$ e outra hipotética $\left(H_{0}\right)$. Desta forma, o teste se baseia em duas hipóteses:

\section{$H_{0}$ : Os dados seguem distribuição normal - hipotética \\ $H_{1}$ : Os dados não seguem distribuição normal - empírica}

Antes de iniciar a execução dos procedimentos metodológicos, foram excluídas as áreas de represa contidas nos mapas de todas as variáveis geoambientais, visto que são locais onde não há a possibilidade ocorrer queimadas. Além disto, no caso do NDVI, os pixels menores que 0,172 foram reclassificados para o valor máximo observado $(0,777)$, visto que estão relacionados a solo exposto, rocha exposta e outros corpos d'água, feições em que não ocorrem incêndios.

Seguindo os procedimentos demonstrados por Taylor (1977) para calcular parâmetros estatísticos do teste $K S$, foram encontrados os valores de área das oito classes de cada variável. Em seguida, foram calculados os valores de Ocorrência observada $\left(O_{O}\right)$, que mostram, quantitativamente, a distribuição dos pontos de áreas críticas de recorrência de queimadas (amostra empírica), dentro das classes de uma variável. Foi calculada também a Ocorrência Esperada $\left(O_{E}\right)$, que demonstra a distribuição dos pontos de áreas críticas em uma variável, proporcionalmente à área das classes (valores hipotéticos, que simulam a distribuição normal esperada).

Por seguinte, os valores de $O_{O}$ e $O_{E}$ foram convertidos em Frequência Observada $\left(F_{O}\right)$ e Frequência Esperada $\left(F_{E}\right)$. Como o $K S$ utiliza valores cumulativos, foi calculada a Frequência acumulada observada $\left(F_{A O}\right)$ e Frequência acumulada esperada $\left(F_{A E}\right)$. Foram encontradas as diferenças entre $F_{A O}$ e $F_{A E}$, em módulo, resultando nos valores $D$ de cada classe. O maior valor de $D$ é o $D$ máximo $\left(D_{M A ́ X}\right)$, e para avaliar o grau de aderência entre as duas distribuições, o $D_{M A ́ X}$ deve ser comparado ao $D$ crítico $\left(D_{C}\right)$, a um determinado nível de significância. Os valores críticos de $D$ podem ser consultados em Taylor (1977). Em relação à comparação entre os valores de $D_{M A ́ X}$ e $D_{C}$ :

$D_{M A ́ x} \geq D_{C}$ : Será comprovada a hipótese $H_{l}$ e rejeitada a hipótese nula $H_{0}$ (distribuição não-normal). Neste caso, haverá relação espacial entre áreas críticas de recorrência de queimadas e uma variável geoambiental. Quanto maior o $D_{M A ́ X}$, maior será a influência da variável.

$D_{M A ́ X}<D_{C}$ : Será rejeitada a hipótese $H_{l}$ e aceita a hipótese nula $H_{0}$ (distribuição normal). A distribuição das áreas críticas de recorrência de queimadas ocorre de maneira semelhante dentro das classes de uma variável, havendo baixa influência da mesma.

Se comprovada a hipótese $H_{l}$, para certa variável, esta poderá ser utilizada na modelagem. Contudo, caso seja comprovada a hipótese $H_{0}$ e rejeitada a hipótese $H_{l}$, esta variável deverá ser descartada da modelagem. Além disto, considerando que quanto maior for o $D_{M A ́ X}$ de uma variável, maior será a sua influência na 
propagação de incêndios, os valores de $D_{M A ́ X}$ podem ser utilizados como pesos. Como os valores de $D_{M A ́ x}$ estão associados à escala de valores do teste $K S$, optou-se por normalizá-los para uma escala entre [0 - 1].

Neste artigo, propõe-se gerar um modelo de perigo de propagação de queimadas sem rigidez de classes. Foi então aplicada a padronização $F u z z y$ das variáveis geoambientais, utilizando a função de transferência linear. Nas variáveis hipsometria, índice de convexidade, efeito do vento e declividade, pixels de valores altos estão associados a características que propiciam a propagação, portanto, o valor mínimo identificado foi reescalonado para 0 , e o máximo para 1 , assim como os valores intermediários entre eles. Por outro lado, nas variáveis NDVI, densidade de vias e densidade de drenagem, os valores baixos são os que mais propiciam a propagação, deste modo, o valor mínimo identificado foi reescalonado de maneira oposta, isto é, para 1, e o máximo para 0 .

O perigo de propagação de queimadas $(P P Q)$, em cada pixel do mapa, foi calculado por meio de álgebra de mapas em SIG, aplicando-se o modelo espacial ponderado da Equação 1:

$$
P P Q=(V 1 . P 1)+(V 2 . P 2)+\ldots+(V n . P n)
$$

Onde: $V_{l}, V_{2} e V_{n}$ são, respectivamente, o valor de um pixel na variável 1 , na variável 2 e em $n$ variáveis; $P_{1}, P_{2}$ e $P_{n}$ são, respectivamente, o peso da variável 1, da variável 2 e de $n$ variáveis. Este modelo permite a inserção de qualquer variável geoambiental, desde que tenha sido realizada a padronização Fuzzy da mesma.

\subsection{Validação do Modelo de Perigo de Propagação de Queimadas}

Para realizar a validação deste modelo, foram selecionadas todas as imagens Landsat OLI disponíveis entre abril e novembro, dos anos de 2016 e 2017. Sobre estas imagens, foi realizado o mapeamento das queimadas ocorridas em cada ano, de forma visual. Na sequência, o mapa de perigo de propagação de queimadas foi dividido em 20 classes, por meio da técnica de classificação de intervalos quantil, e calculouse o valor do pixel da mediana de cada classe. Foram também identificados os valores de área queimada em cada classe de perigo de propagação.

A validação foi realizada através da determinação do grau de associação entre os valores da mediana das classes de perigo de propagação de queimadas (variável $X$ ) e área das queimadas ocorridas nestas classes nos anos de 2016 e 2017 (variável Y). Este grau de associação foi determinado através do coeficiente de correlação de Pearson ( $r$ ), e a avaliação do nível de significância de $r$ foi realizada através do teste $t$ de Student, como demonstra Ferreira (2014). Foi utilizado o software estatístico MedCalc na geração dos coeficientes e do gráfico de dispersão. Foi também realizado trabalho de campo no PNSC, entre 18 e 20 de novembro de 2017, para a verificação dos resultados e observações in loco.

\section{Resultados e Discussão}

\subsection{Apresentação do Modelo de Perigo de Propagação de Queimadas}

O modelo de perigo de propagação de queimadas, proposto neste artigo, foi aplicado no PNSC e em sua ZA, a partir das informações contidas em sete variáveis geoambientais: hipsometria (Figura 3A), declividade (Figura 3B), índice de convexidade da superfície (Figura 3C), efeito do vento nas vertentes (Figura 3D), NDVI (Figura 3E), densidade de drenagem (Figura 3F) e densidade de vias de circulação (Figura 3G). Estas variáveis auxiliam na compreensão do espalhamento do fogo nesta UC, e suas características serão discutidas mais à frente. 

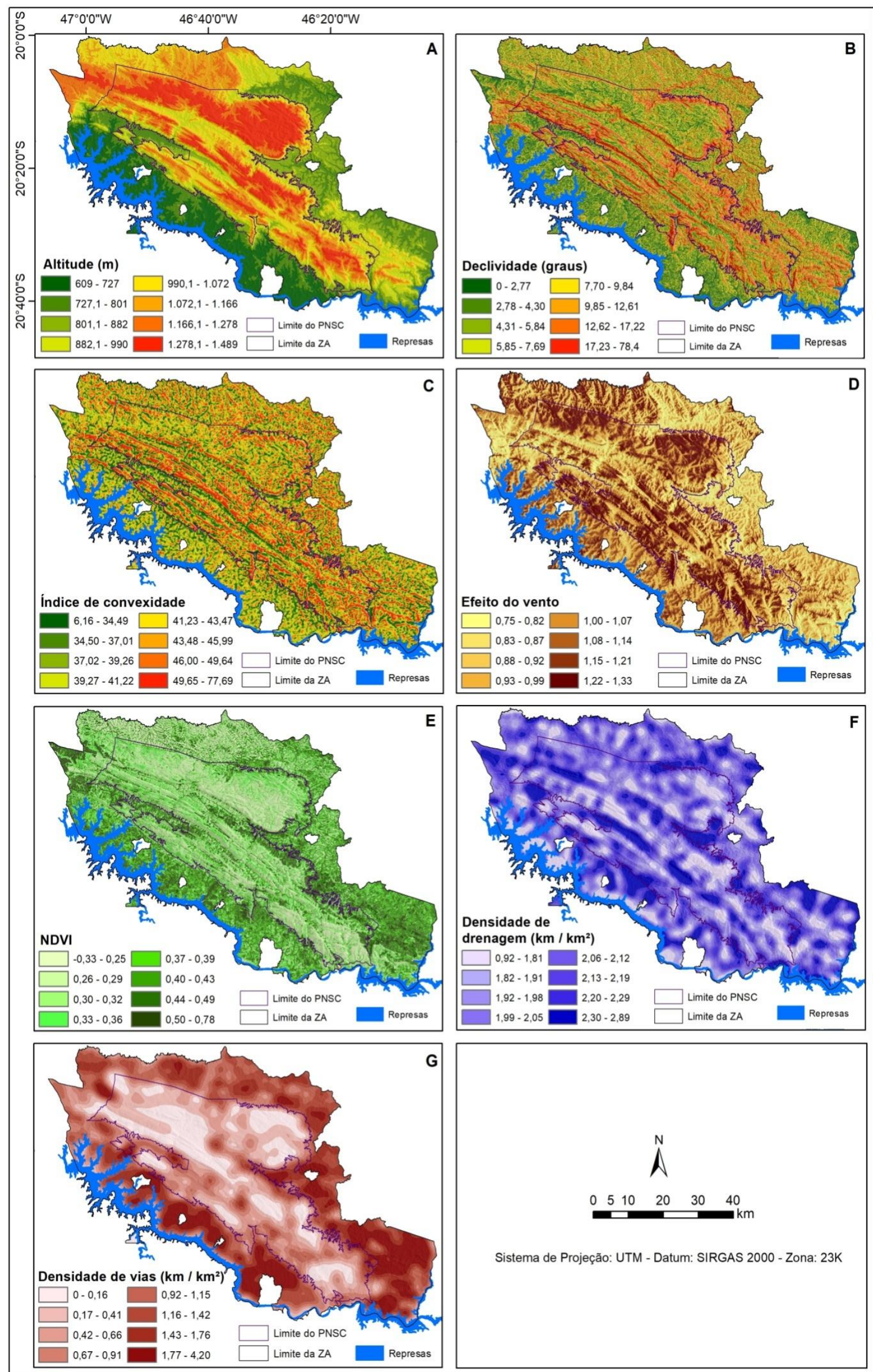

Figura 3: Variáveis geoambientais possivelmente associadas com a propagação de queimadas no Parque Nacional da Serra da Canastra. 
Observou-se que a distribuição observada $\left(O_{O}\right)$ dos 664 pontos amostrais localizados em áreas críticas de recorrência de queimadas (amostra empírica) é irregular ao longo das classes das variáveis geoambientais. Algumas classes concentraram maior número de pontos, enquanto, em outras, os pontos se distribuíram em menor quantidade. Ao contrário, na distribuição esperada $\left(O_{E}\right)$ (amostra hipotética), os pontos se distribuíram de forma semelhante entre as classes (Tabela 1; Tabela 2; Tabela 3; Tabela 4; Tabela 5; Tabela 6; Tabela 7).

Tabela 1: Ocorrências esperadas e observadas, segundo intervalos de hipsometria.

\begin{tabular}{ccccccccc}
\hline & & \multicolumn{7}{c}{ Intervalos de classes de hipsometria } \\
Parâmetros estatísticos & $609-$ & $727,1-$ & $801,1-$ & $882,1-$ & $990,1-$ & $1.072,1$ & $1.166,1$ & $1.278,1$ \\
& 727 & 801 & 882 & 990 & 1.072 & -1.166 & -1.278 & -1.489 \\
\hline Área da classe $\left(\mathrm{km}^{2}\right)$ & 560,25 & 560,2 & 553,05 & 553,95 & 551,14 & 554,17 & 552,14 & 545,58 \\
Área da classe $(\%)$ & 12,65 & 12,64 & 12,48 & 12,50 & 12,44 & 12,51 & 12,46 & 12,31 \\
Ocorrência esperada & 83,97 & 83,96 & 82,89 & 83,02 & 82,6 & 83,05 & 82,75 & 81,77 \\
Ocorrência observada & 0 & 0 & 3 & 10 & 39 & 104 & 206 & 302 \\
\hline
\end{tabular}

Tabela 2: Ocorrências esperadas e observadas, segundo intervalos de declividade.

\begin{tabular}{ccccccccc}
\hline & & \multicolumn{7}{c}{ Intervalos de classes de declividade } \\
Parâmetros estatísticos & $0-2,77$ & $2,78-$ & $4,31-$ & $5,85-$ & $7,70-$ & $9,85-$ & $12,62-$ & $17,23-$ \\
& & 4,30 & 5,84 & 7,69 & 9,84 & 12,61 & 17,22 & 78,40 \\
\hline Área da classe $\left(\mathrm{km}^{2}\right)$ & 527,11 & 541,03 & 569,81 & 614,31 & 579,85 & 536,84 & 539,35 & 522,17 \\
Área da classe $(\%)$ & 11,9 & 12,21 & 12,86 & 13,87 & 13,09 & 12,12 & 12,17 & 11,79 \\
Ocorrência esperada & 78,1 & 81,08 & 85,4 & 92,07 & 86,90 & 80,46 & 80,83 & 78,1 \\
Ocorrência observada & 48 & 67 & 77 & 85 & 108 & 103 & 101 & 75 \\
\hline
\end{tabular}

Tabela 3: Ocorrências esperadas e observadas, segundo intervalos de índice de convexidade.

\begin{tabular}{ccccccccc}
\hline & \multicolumn{7}{c}{ Intervalos de classes de índice de convexidade } \\
\cline { 3 - 9 } Parâmetros estatísticos & $6,16-$ & $34,50-$ & $37,02-$ & $39,27-$ & $41,23-$ & $43,48-$ & $46,00-$ & $49,65-$ \\
& 34,49 & 37,01 & 39,26 & 41,22 & 43,47 & 45,99 & 49,64 & 77,69 \\
\hline Área da classe $\left(\mathrm{km}^{2}\right)$ & 509,58 & 532,40 & 607,35 & 568,79 & 610,61 & 562,25 & 544,62 & 494,88 \\
Área da classe $(\%)$ & 11,50 & 12,02 & 13,71 & 12,84 & 13,78 & 12,69 & 12,29 & 11,17 \\
Ocorrência esperada & 76,37 & 79,79 & 91,02 & 85,25 & 91,51 & 84,27 & 81,62 & 74,17 \\
Ocorrência observada & 27 & 25 & 36 & 52 & 70 & 89 & 154 & 211 \\
\hline
\end{tabular}

Tabela 4: Ocorrências esperadas e observadas, segundo intervalos de efeito do vento.

\begin{tabular}{ccccccccc}
\hline & \multicolumn{7}{c}{ Intervalos de classes de efeito do vento } \\
Parâmetros estatísticos & $0,75-$ & $0,83-$ & $0,88-$ & $0,93-$ & $1,0-$ & $1,08-$ & $1,15-$ & $1,22-$ \\
& 0,82 & 0,87 & 0,92 & 0,99 & 1,07 & 1,14 & 1,21 & 1,33 \\
\hline Área da classe $\left(\mathrm{km}^{2}\right)$ & 547,39 & 567,26 & 570,70 & 551,94 & 549,98 & 547,31 & 552,78 & 543,10 \\
Área da classe $(\%)$ & 12,36 & 12,80 & 12,88 & 12,46 & 12,41 & 12,35 & 12,48 & 12,26 \\
Ocorrência esperada & 82,04 & 85,02 & 85,53 & 82,72 & 82,43 & 82,03 & 82,85 & 81,40 \\
Ocorrência observada & 3 & 23 & 43 & 56 & 60 & 97 & 180 & 202 \\
\hline
\end{tabular}

Tabela 5: Ocorrências esperadas e observadas, segundo intervalos de NDVI.

\begin{tabular}{ccccccccc}
\hline & \multicolumn{7}{c}{ Intervalos de classes de NDVI } \\
Parâmetros estatísticos & $0,491-$ & $0,434-$ & $0,395-$ & $0,356-$ & $0,321-$ & $0,290-$ & $0,255-$ & $-0,333$ \\
& 0,777 & 0,490 & 0,433 & 0,394 & 0,355 & 0,320 & 0,289 & $-0,254$ \\
\hline Área da classe $\left(\mathrm{km}^{2}\right)$ & 519,33 & 514,10 & 516,65 & 575,74 & 600,22 & 573,40 & 620,68 & 510,31 \\
Área da classe $(\%)$ & 11,52 & 14,01 & 12,94 & 13,55 & 13,00 & 11,66 & 11,60 & 11,72 \\
Ocorrência esperada & 76,48 & 93,02 & 85,94 & 89,96 & 86,29 & 77,43 & 77,05 & 77,83 \\
Ocorrência observada & 0 & 3 & 9 & 37 & 97 & 153 & 190 & 175 \\
\hline
\end{tabular}

Tabela 6: Ocorrências esperadas e observadas, segundo intervalos de densidade drenagem.

\begin{tabular}{ccccccccc}
\hline & \multicolumn{7}{c}{ Intervalos de classes de densidade de drenagem } \\
Parâmetros estatísticos & $2,30-$ & $2,20-$ & $2,13-$ & $2,06-$ & $1,99-$ & $1,92-$ & $1,82-$ & $0,92-$ \\
& 2,89 & 2,29 & 2,19 & 2,12 & 2,05 & 1,98 & 1,91 & 1,81 \\
& 514,87 & 537,00 & 522,17 & 562,56 & 594,76 & 597,10 & 550,70 & 551,30 \\
Área da classe $\left(\mathrm{km}^{2}\right)$ & 11,62 & 12,12 & 11,79 & 12,70 & 13,42 & 13,48 & 12,43 & 12,44 \\
Área da classe $(\%)$ & 77,16 & 80,48 & 78,26 & 84,31 & 89,14 & 89,49 & 82,53 & 82,62 \\
Ocorrência esperada & 19 & 34 & 40 & 49 & 79 & 126 & 145 & 172 \\
Ocorrência observada & & & & & & &
\end{tabular}


Tabela 7: Ocorrências esperadas e observadas, segundo intervalos de densidade de vias de circulação.

\begin{tabular}{ccccccccc}
\hline & & \multicolumn{7}{c}{ Intervalos de classes de densidade de vias de circulacão } \\
Parâmetros estatísticos & $1,77-$ & $1,43-$ & $1,16-$ & $0,92-$ & $0,67-$ & $0,42-$ & $0,17-$ & \\
& 4,2 & 1,76 & 1,42 & 1,15 & 0,91 & 0,66 & 0,41 & 0,16 \\
\hline Área da classe $\left(\mathrm{km}^{2}\right)$ & 534,97 & 567,63 & 559,73 & 545,32 & 551,20 & 550,37 & 544,05 & 577,42 \\
Área da classe $(\%)$ & 12,07 & 12,81 & 12,63 & 12,31 & 12,44 & 12,42 & 12,28 & 13,03 \\
Ocorrência esperada & 80,17 & 85,07 & 83,88 & 81,72 & 82,61 & 82,48 & 81,53 & 86,53 \\
Ocorrência observada & 0 & 0 & 3 & 21 & 55 & 150 & 192 & 243 \\
\hline
\end{tabular}

Com o aumento da altitude, da declividade, dos índices de convexidade da superfície e do efeito do vento sobre as vertentes, houve um incremento no número de pontos de áreas críticas de recorrência de queimadas observados. Por outro lado, com o aumento do NDVI, da densidade de vias e da densidade de drenagem, houve redução do número de pontos observados. Esta irregularidade na distribuição dos pontos empiricamente mapeados está associada à influência de fatores locacionais, os quais contribuem com o aumento do perigo de propagação de queimadas.

Na sequência, foram calculados os valores de $F_{O}$ e $F_{E}$, seus valores acumulativos e as diferenças entre eles (Tabela 8; Tabela 9; Tabela 10; Tabela 11; Tabela 12; Tabela 13; Tabela 14. Os valores máximos de $D$, para cada variável, estão destacados em negrito.

Tabela 8: Resultado da aplicação do teste Kolmogorov-Smirnov à variável hipsometria.

\begin{tabular}{|c|c|c|c|c|c|c|c|c|}
\hline \multirow[b]{2}{*}{ Parâmetros estatísticos } & \multicolumn{8}{|c|}{ Intervalos de classes de hipsometria } \\
\hline & $\begin{array}{c}609- \\
727\end{array}$ & $\begin{array}{c}727,1 \text { - } \\
801\end{array}$ & $\begin{array}{c}801,1- \\
882\end{array}$ & $\begin{array}{c}882,1- \\
990\end{array}$ & $\begin{array}{c}990,1- \\
1.072\end{array}$ & $\begin{array}{l}1.072,1 \\
-1.166\end{array}$ & $\begin{array}{l}1.166,1 \\
-1.278\end{array}$ & $\begin{array}{r}1.278,1 \\
-1.489 \\
\end{array}$ \\
\hline & 0,0000 & 0,0000 & & & & & 0,3102 & 0,4548 \\
\hline & & & & & & & & \\
\hline Frec & 0 , & 0 & 15 & 96 & 0,0 & 49 & 52 & 000 \\
\hline Freq. esperada acumulada & 0,1265 & 0,2529 & 0,3777 & 0,5028 & 0,6272 & 0,7522 & 0,8769 & 1,0000 \\
\hline Diferenças $\left|F_{A O}-F_{A E}\right|$ & 0,1265 & 0,2529 & 0,3732 & 0,4832 & $\mathbf{0 , 5 4 8 8}$ & 0,5173 & 0,3317 & 0,0000 \\
\hline
\end{tabular}

Tabela 9: Resultado da aplicação do teste Kolmogorov-Smirnov à variável declividade.

\begin{tabular}{cccccccccc}
\hline \multirow{2}{*}{ Parâmetros estatísticos } & & \multicolumn{7}{c}{ Intervalos de classes de declividade } \\
& $0-2,77$ & $2,78-$ & $4,31-$ & $5,85-$ & $7,70-$ & $9,85-$ & $12,62-$ & $17,23-$ \\
\hline Frequência observada & 0,0723 & 0,1009 & 5,84 & 7,69 & 9,84 & 12,61 & 17,22 & 78,40 \\
Frequência esperada & 0,1190 & 0,1221 & 0,1286 & 0,1280 & 0,1387 & 0,1627 & 0,1551 & 0,1521 & 0,1130 \\
Freq. observ. acumulada & 0,0723 & 0,1732 & 0,2892 & 0,4172 & 0,5798 & 0,1212 & 0,1217 & 0,1179 \\
Freq. esperada acumulada & 0,1190 & 0,2411 & 0,3697 & 0,5084 & 0,6392 & 0,7604 & 0,8870 & 1,0000 \\
Diferenças $\left|\mathrm{F}_{\mathrm{AO}}-\mathrm{F}_{\mathrm{AE}}\right|$ & 0,0467 & 0,0679 & 0,0805 & $\mathbf{0 , 0 9 1 2}$ & 0,0594 & 0,0255 & 0,0049 & 0,00000 \\
\hline
\end{tabular}

Tabela 10: Resultado da aplicação do teste Kolmogorov-Smirnov à variável índice de convexidade.

\begin{tabular}{cccccccccc}
\hline & \multicolumn{8}{c}{ Intervalos de classes de índice de convexidade } \\
Parâmetros estatísticos & $6,16-$ & $34,50-$ & $37,02-$ & $39,27-$ & $41,23-$ & $43,48-$ & $46,00-$ & $49,65-$ \\
& 34,49 & 37,01 & 39,26 & 41,22 & 43,47 & 45,99 & 49,64 & 77,69 \\
\hline Frequência observada & 0,0407 & 0,0377 & 0,0542 & 0,0783 & 0,1054 & 0,1340 & 0,2319 & 0,3178 \\
Frequência esperada & 0,1150 & 0,1202 & 0,1371 & 0,1284 & 0,1378 & 0,1269 & 0,1229 & 0,1117 \\
Freq. observ. acumulada & 0,0407 & 0,0783 & 0,1325 & 0,2108 & 0,3163 & 0,4503 & 0,6822 & 1,0000 \\
Freq. esperada acumulada & 0,1150 & 0,2352 & 0,3723 & 0,5007 & 0,6385 & 0,7654 & 0,8883 & 1,0000 \\
Diferenças $\left|\mathrm{F}_{\mathrm{AO}}-\mathrm{F}_{\mathrm{AE}}\right|$ & 0,0744 & 0,1569 & 0,2397 & 0,2898 & $\mathbf{0 , 3 2 2 2}$ & 0,3151 & 0,2061 & 0,0000 \\
\hline
\end{tabular}

Tabela 11: Resultado da aplicação do teste Kolmogorov-Smirnov à variável índice de efeito do vento.

\begin{tabular}{ccccccccc}
\hline & & \multicolumn{7}{c}{ Intervalos de classes de efeito do vento } \\
Parâmetros estatísticos & $0,75-$ & $0,83-$ & $0,88-$ & $0,93-$ & $1,0-$ & $1,08-$ & $1,15-$ & $1,22-$ \\
& 0,82 & 0,87 & 0,92 & 0,99 & 1,07 & 1,14 & 1,21 & 1,33 \\
\hline Frequência observada & 0,0045 & 0,0346 & 0,0648 & 0,0843 & 0,0904 & 0,1461 & 0,2711 & 0,3042 \\
Frequência esperada & 0,1236 & 0,1280 & 0,1288 & 0,1246 & 0,1241 & 0,1235 & 0,1248 & 0,1226 \\
Freq. observ. acumulada & 0,0045 & 0,0392 & 0,1039 & 0,1883 & 0,2786 & 0,4247 & 0,6958 & 1,0000 \\
Freq. esperada acumulada & 0,1236 & 0,2516 & 0,3804 & 0,5050 & 0,6291 & 0,7526 & 0,8774 & 1,0000 \\
Diferenças $\mid \mathrm{F}_{\mathrm{AO}}-\mathrm{F}_{\mathrm{AE}} \|$ & 0,1190 & 0,2124 & 0,2765 & 0,3167 & $\mathbf{0 , 3 5 0 5}$ & 0,3279 & 0,1816 & 0,0000 \\
\hline
\end{tabular}


Tabela 12: Resultado da aplicação do teste Kolmogorov-Smirnov à variável NDVI.

\begin{tabular}{ccccccccc}
\hline & \multicolumn{7}{c}{ Intervalos de classes de NDVI } \\
Parâmetros estatísticos & $0,491-$ & $0,434-$ & $0,395-$ & $0,356-$ & $0,321-$ & $0,290-$ & $0,255-$ & $-0,333$ \\
& 0,777 & 0,490 & 0,433 & 0,394 & 0,355 & 0,320 & 0,289 & $-0,254$ \\
\hline Frequência observada & 0,0000 & 0,0045 & 0,0136 & 0,0557 & 0,1461 & 0,2304 & 0,2861 & 0,2636 \\
Frequência esperada & 0,1152 & 0,1401 & 0,1294 & 0,1355 & 0,1300 & 0,1166 & 0,1160 & 0,1172 \\
Freq. observ. acumulada & 0,0000 & 0,0045 & 0,0181 & 0,0738 & 0,2199 & 0,4503 & 0,7364 & 1,0000 \\
Freq. esperada acumulada & 0,1152 & 0,2553 & 0,3847 & 0,5202 & 0,6501 & 0,7667 & 0,8828 & 1,0000 \\
Diferenças $\mid \mathrm{F}_{\mathrm{AO}}-\mathrm{F}_{\mathrm{AE}} \|$ & 0,1152 & 0,2508 & 0,3666 & $\mathbf{0 , 4 4 6 4}$ & 0,4302 & 0,3164 & 0,1463 & 0,0000 \\
\hline
\end{tabular}

Tabela 13: Resultado da aplicação do teste Kolmogorov-Smirnov à variável densidade de drenagem.

\begin{tabular}{cccccccccc}
\hline & \multicolumn{7}{c}{ Intervalos de classes de densidade drenagem } \\
Parâmetros estatísticos & $2,30-$ & $2,20-$ & $2,13-$ & $2,06-$ & $1,99-$ & $1,92-$ & $1,82-$ & $0,92-$ \\
& 2,89 & 2,29 & 2,19 & 2,12 & 2,05 & 1,98 & 1,91 & 1,81 \\
\hline Frequência observada & 0,0286 & 0,0512 & 0,0602 & 0,0738 & 0,1190 & 0,1898 & 0,2184 & 0,2590 \\
Frequência esperada & 0,1162 & 0,1212 & 0,1179 & 0,1270 & 0,1342 & 0,1348 & 0,1243 & 0,1244 \\
Freq. observ. acumulada & 0,0286 & 0,0798 & 0,1401 & 0,2139 & 0,3328 & 0,5226 & 0,7410 & 1,0000 \\
Freq. esperada acumulada & 0,1162 & 0,2374 & 0,3553 & 0,4823 & 0,6165 & 0,7513 & 0,8756 & 1,0000 \\
Diferenças $\left|\mathrm{F}_{\mathrm{AO}}-\mathrm{F}_{\mathrm{AE}}\right|$ & 0,0876 & 0,1576 & 0,2152 & 0,2684 & $\mathbf{0 , 2 8 3 7}$ & 0,2287 & 0,1346 & 0,0000 \\
\hline
\end{tabular}

Tabela 14: Resultado da aplicação do teste Kolmogorov-Smirnov à variável densidade de vias de circulação.

\begin{tabular}{cccccccccc}
\hline & & \multicolumn{7}{c}{ Intervalos de classes de densidade vias de circulacão } \\
Parâmetros estatísticos & $1,763-$ & $1,417-$ & $1,154-$ & $0,907-$ & $0,659-$ & $0,412-$ & $0,165-$ & $0-$ \\
& 4,2 & 1,762 & 1,416 & 1,153 & 0,906 & 0,658 & 0,411 & 0,164 \\
\hline Frequência observada & 0,0000 & 0,0000 & 0,0045 & 0,0316 & 0,0828 & 0,2259 & 0,2892 & 0,3660 \\
Frequência esperada & 0,1207 & 0,1281 & 0,1263 & 0,1231 & 0,1244 & 0,1242 & 0,1228 & 0,1303 \\
Freq. observ. acumulada & 0,0000 & 0,0000 & 0,0045 & 0,0361 & 0,1190 & 0,3449 & 0,6340 & 1,0000 \\
Freq. esperada acumulada & 0,1207 & 0,2489 & 0,3752 & 0,4983 & 0,6227 & 0,7469 & 0,8697 & 1,0000 \\
Diferenças $\left|\mathrm{F}_{\mathrm{AO}}-\mathrm{F}_{\mathrm{AE}}\right|$ & 0,1207 & 0,2489 & 0,3707 & 0,4621 & $\mathbf{0 , 5 0 3 7}$ & 0,4020 & 0,2356 & 0,0000 \\
\hline
\end{tabular}

Considerando que o $n$ da amostra é igual a 664, e a um nível de significância de $0,05, D_{C}=0,0527$ (TAYLOR, 1977). Todas as variáveis trabalhadas apresentaram $D_{M A ́ X}>D_{C}$. Deste modo, comprovou-se a hipótese $H_{1}$ e rejeitou-se a hipótese nula $H_{0}$, assegurando que as distribuições avaliadas são não-normais. Deste modo, há dependência espacial entre os pontos de áreas críticas de recorrência de queimadas e as variáveis geoambientais trabalhadas. Os valores de $D_{M A X}$ de cada variável, assim como os pesos normalizados, estão relacionados na Tabela 15, em ordem de importância.

Tabela 15: Valores de $D$ máximo e dos pesos normalizados das variáveis, obtidos através do teste $K S$.

\begin{tabular}{ccc}
\hline Variável geoambiental & $\boldsymbol{D}_{\boldsymbol{M A ́ X}}$ & $\boldsymbol{P}$ \\
\hline Hipsometria & 0,5488 & 0,2155 \\
Densidade de vias de circulação & 0,5037 & 0,1978 \\
Índice de vegetação (NDVI) & 0,4464 & 0,1753 \\
Efeito do vento & 0,3505 & 0,1376 \\
Índice de convexidade & 0,3222 & 0,1265 \\
Densidade de drenagem & 0,2837 & 0,1114 \\
Declividade & 0,0912 & 0,0358 \\
\hline
\end{tabular}

O mapa de perigo de propagação de queimadas (Figura 4), gerado através do cruzamento dos das variáveis geoambientais e aplicação dos pesos obtidos pelo teste $K S$, revela cartograficamente a heterogeneidade espacial do perigo nos diferentes ambientes do PNSC. Neste produto, os valores são apresentados em escala contínua Fuzzy, sendo que os pixels com valores próximos de 1,0 estão associados a locais com alta probabilidade de perigo de propagação de queimadas, enquanto os pixels com valores próximos de 0,0 , locais com baixa probabilidade de perigo de propagação 


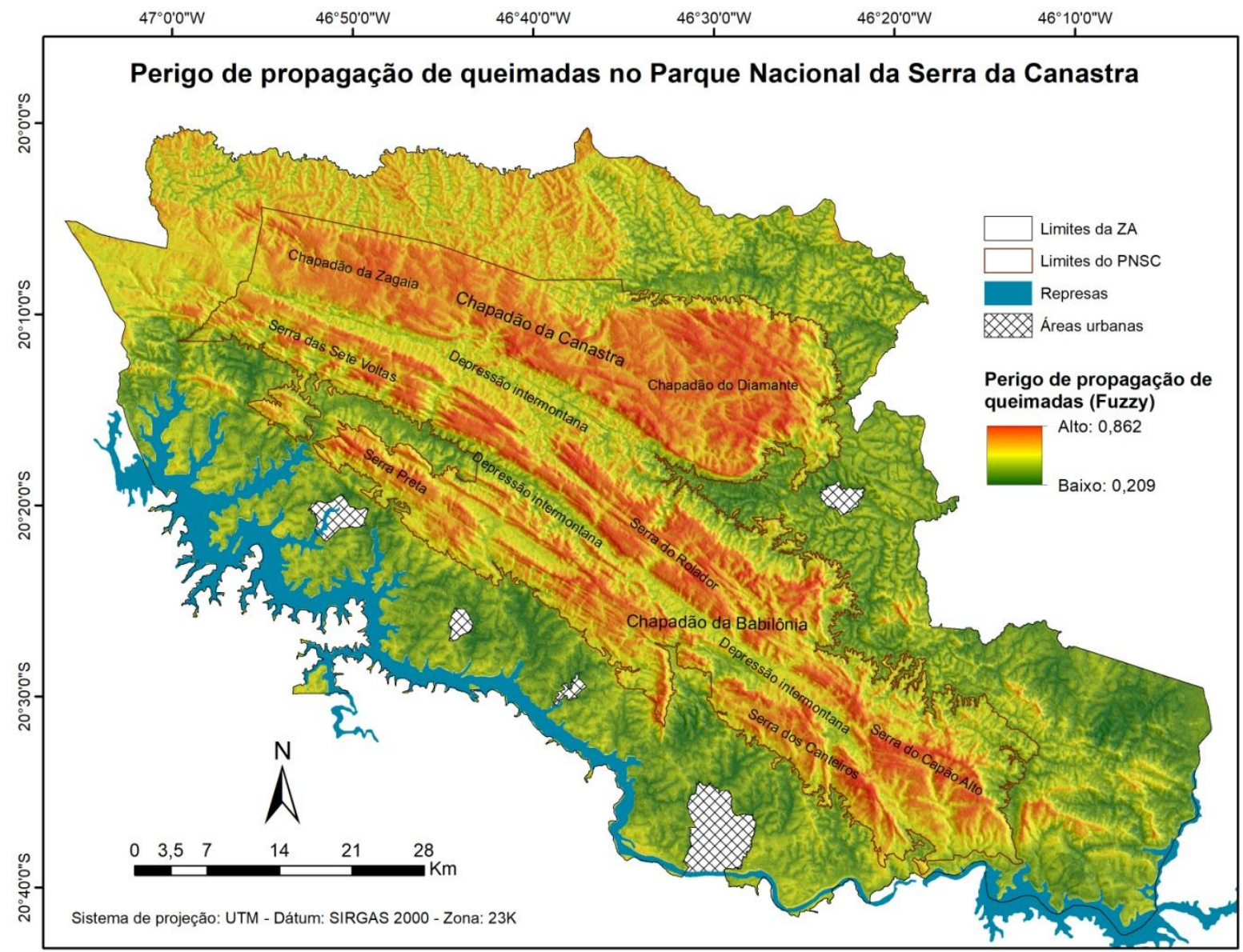

Figura 4: Perigo de propagação de queimadas no Parque Nacional da Serra da Canastra, em escala Fuzzy.

O modelo gerado permitiu identificar que, o interior dos Chapadões da Canastra e da Babilônia, são as áreas com maior perigo de propagação de queimadas. Estes locais apresentam altitudes elevadas, superiores a $1.200 \mathrm{~m}$, podendo chegar a quase $1.500 \mathrm{~m}$, e são basicamente compostos por fitofisionomias campestres, especialmente os campos limpos. No período seco, a vegetação herbácea torna-se senescente e disponibiliza alta quantidade de combustível seco na superfície, o que eleva o potencial de propagação (FRANKE et al., 2018).

De modo geral, as vertentes dos Chapadões recebem alto efeito do vento e, associado com as médias a altas declividades e concentrações de vertentes convexas, a propagação torna-se mais intensa, pois os ventos disponibilizam oxigênio para a combustão e direcionam os incêndios (TORRES, 2006). Além disto, o interior dos Chapadões tem baixas densidades de vias de circulação, o que dificulta o acesso aos focos ativos.

O interior do Chapadão da Babilônia está geralmente relacionado a baixas densidades de drenagem, facilitando a propagação de queimadas, o que no Chapadão da Canastra é mais variável. Os corpos d'água funcionam como barreiras naturais ao fogo, pois, os fundos de vale estão geralmente associados a fitofisionomias arbóreas, como matas ciliares ou de galeria, há menor acumulação de combustível morto, há maior adensamento de vertentes côncavas e o efeito do vento é menor. Por isto, a intensidade do fogo nos fundos de vale é mais reduzida.

As depressões intermontanas, que se desenvolvem entre os Chapadões, estão associadas a médios valores de perigo de propagação. As suas altitudes são menos elevadas, em torno de $900 \mathrm{~m}$. Além disto, os índices de convexidade das vertentes são baixos, observa-se alta densidade de drenagem e o efeito do vento é baixo, fatores que reduzem o perigo. Entretanto, a maior parte das depressões é formada por vegetação herbácea, altamente inflamável no período seco e, na maioria das vezes, a densidade de vias é média ou baixa, aumentando o perigo de propagação.

A noroeste e centro-norte da ZA, o perigo é médio nas médias e nas altas encostas, especialmente aquelas voltadas a SW, W e NW, pois o efeito do vento é alto, propiciando o espalhamento do fogo. Nas altas encostas, os índices de convexidade são elevados e a altitude pode chegar a $1.200 \mathrm{~m}$. Estas vertentes possuem baixos índices de vegetação, associados a formações campestres, utilizadas como pastagem na pecuária, e se aplica o fogo como ferramenta de manejo (MMA et al. 2018). Contudo, as densidades de drenagem e de vias 
são médias a altas, funcionando como barreiras à propagação. Nos fundos de vale, os valores de perigo são baixos, visto que estão geralmente associados a vegetação arbórea, baixo efeito do vento e baixa convexidade.

A leste da ZA predomina o baixo perigo. As altitudes são baixas, chegando geralmente a até $900 \mathrm{~m}$. Os índices de vegetação variam entre baixos, em áreas de pastagem, a altos, no caso de matas que estão nas bordas dos Chapadões, topos de morros convexos ou que acompanham a drenagem. O efeito do vento é baixo, pois o vento predominante é interceptado pelos Chapadões. As densidades de drenagem e de vias são geralmente altas, o que não favorece a propagação do fogo.

Por fim, a região localizada ao sul da ZA, próxima das barragens formadas no rio Grande, apresenta baixo perigo. Este local está relacionado a baixas elevações, que não ultrapassam os $800 \mathrm{~m}$, e as vertentes têm baixa e média convexidade. Os campos foram transformados em cultivos de café, cana, banana, milho e soja, e o fogo é menos utilizado em seu manejo em relação às pastagens, pois os incêndios podem ser danosos a muitos deles (MMA et al. 2018). Predominam altas densidades de vias de circulação e drenagem. Entre as variáveis trabalhadas, a única que propicia o avanço de queimadas é o efeito do vento, que apresenta médios a altos valores.

Apesar do modelo ter mostrado que as áreas mais propensas à propagação de queimadas no PNSC ocorrem no interior dos Chapadões da Canastra e da Babilônia (Figura 4), o grau de reincidência dos eventos se difere entre estas zonas (Figura 2A). O Chapadão da Canastra abrange áreas com valores de recorrência situados próximos ou pouco superiores à média de toda a área de estudo, enquanto no interior da Babilônia, os valores estão muito acima da média (MESSIAS; FERREIRA, 2017). Deste modo, mesmo que os dois Chapadões apresentem características geoambientais semelhantes, o que faz com que perigo de propagação seja potencialmente similar, há fatores que contribuem para que o regime do fogo se diferencie entre essas duas zonas.

O Chapadão da Canastra foi regularizado no período de criação parque, mas, mesmo assim, ocorrem atividades antrópicas conflitantes associadas à ignição, como a presença de uma estrada de $67 \mathrm{~km}$, linhas de transmissão de energia elétrica e atividades turísticas (MMA; IBAMA, 2005). Contudo, a presença institucional inibe os riscos de ignição. Nos períodos críticos de ocorrência de incêndios, desde a criação desta UC, há a brigada de prevenção e combate a incêndios florestais, disponível nas três portarias e, por isto, há detecção e combate precoce do fogo (MMA et al. 2018).

No Chapadão da Babilônia, devido a não regularização, ocorre uma gama maior das atividades que podem levar ao início do fogo, como a presença de linhas de transmissão, atividades agropecuárias, estradas com acesso livre, exploração de quartzito e atividades turísticas (MMA; IBAMA, 2005). Devido ao fato deste Chapadão não ter sido todo desapropriado, a gestão ainda não é total e adequada, o acesso é difícil, não são realizados aceiros, ocorrem queimadas controladas em propriedades particulares, não há monitoramento pela brigada de incêndio e a detecção do fogo é difícil, muitas vezes tardia. O combate não ocorre sempre que um foco é detectado, mas quando possível, pois a força de trabalho disponível não é suficiente para atender os dois Chapadões concomitantemente, priorizando-se o da Canastra (MMA et al. 2018).

\subsection{Validação do Modelo de Perigo de Propagação de Queimadas}

Em 2016, uma área de 95.035,29ha do PNSC e de sua ZA foram atingidos por queimadas, enquanto em 2017, foram 50.112,98ha. A localização espacial das áreas queimadas nestas datas pode ser visualizada na Figura 5, sobrepostas ao perigo de propagação de queimadas, que foi classificado em 20 intervalos pelo método quantil. 


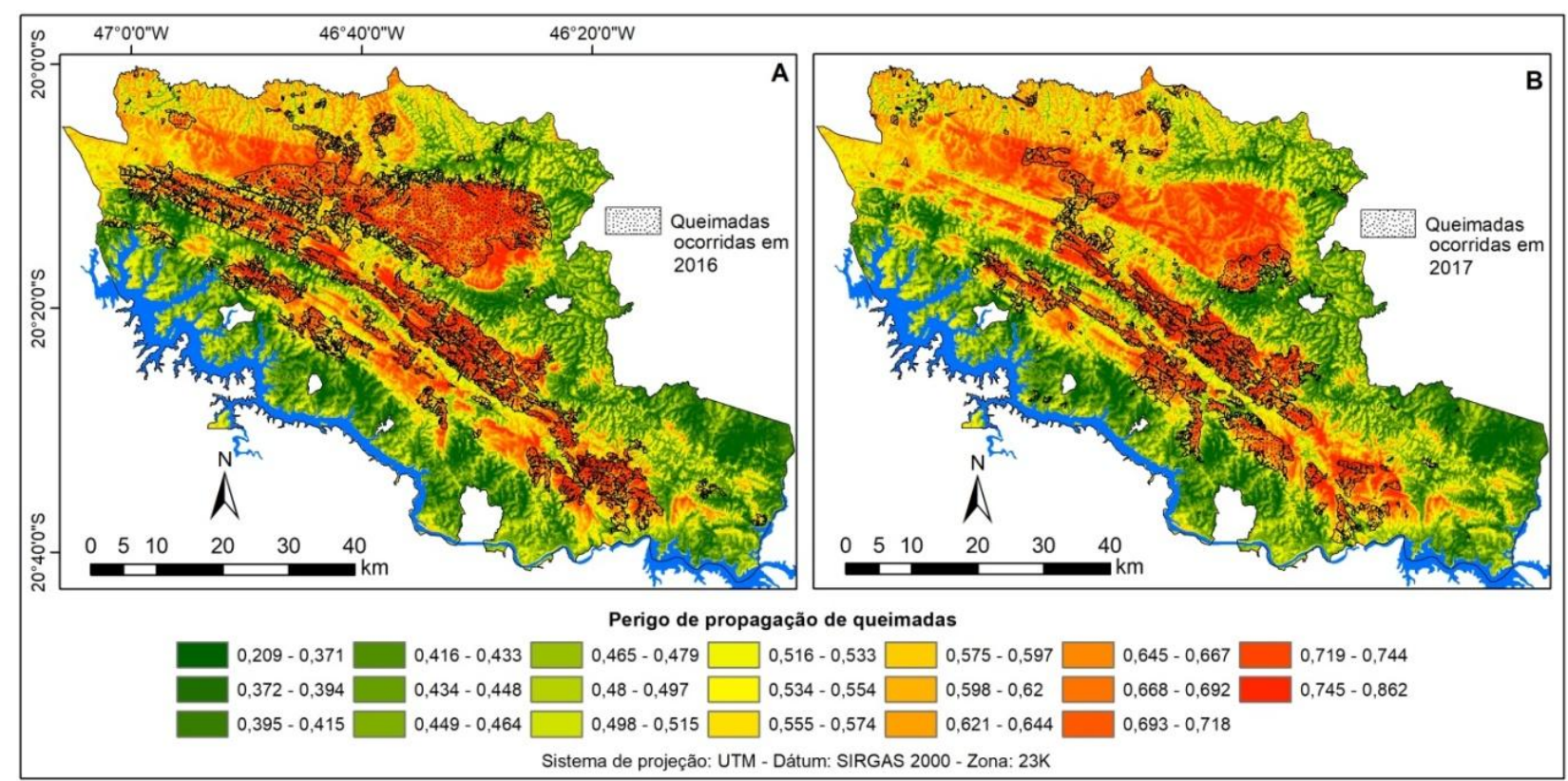

Figura 5: Mapa do perigo de propagação de queimadas e queimadas ocorridas no Parque Nacional da Serra da Canastra em 2016 (A) e 2017 (B).

A partir de um diagrama de dispersão, é possível comprovar a existência de relação linear direta entre os valores da mediana das classes de perigo de propagação (variável $X$ ) e área das queimadas ocorridas nestas classes (variável Y), em 2016 (Figura 6A) e 2017 (Figura 6B). Mesmo que a área do PNSC atingida pelo fogo em 2016 e em 2017 seja demasiadamente diferente, o comportamento da distribuição de área queimada em relação ao perigo de propagação é semelhante ao longo do diagrama de dispersão. Isto é, à medida que se eleva o perigo de propagação, há um incremento na área queimada.
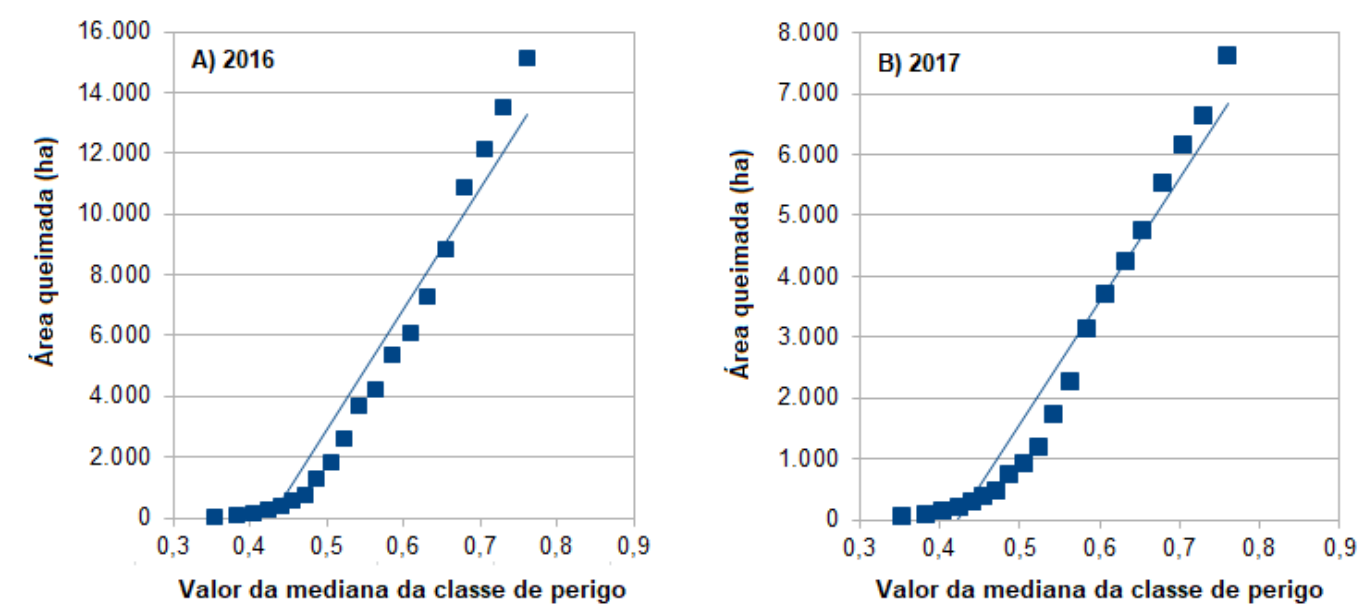

Figura 6: Diagrama de dispersão e linha de tendência da regressão linear entre o valor da mediana das classes de perigo de propagação de queimadas e área das queimadas ocorridas nas classes em 2016 (A) e 2017 (B).

Com a finalidade de validar o modelo, foi calculado o coeficiente de correlação de Pearson, buscando determinar o grau de relacionamento entre o valor da mediana das classes de perigo de propagação e a área das queimadas ocorridas nestas classes. Os resultados mostraram que, para 2016, $r=0,9655$, enquanto para 2017, $r=0,9696$. Os valores obtidos revelam que existe alta correlação entre as classes de perigo de propagação e a área atingida pelo fogo.

Foi realizado o teste $t$ de Student, com a finalidade de avaliar a significância dos coeficientes de correlação calculados e, desta forma, comprovar a confiabilidade do modelo. Os valores $t$ de Student calculados para 2016 e 2017 foram, respectivamente, $t_{C}=16,051$ e $t_{C}=17,452$. Consultando o valor de $t$ crítico tabelado, a um nível de significância $\alpha=0,05, t_{T}=1,734$. Como os valores $t_{C}>t_{T}$, considera-se que o 
coeficiente é significativo. Foi também calculado o valor $P$ da distribuição e, para 2016 e 2017, $p<0,001$. Se $p<\alpha$, considerando $\alpha=0,05$, comprova-se também a significância dos coeficientes.

Estes resultados comprovam que há correlação entre as queimadas ocorridas em 2016 e 2017 e a previsão de perigo estimada pelo modelo no PNSC. Os dados expostos acima certificam que o modelo criado a partir desta pesquisa é satisfatório e, sendo assim, os procedimentos metodológicos apresentados neste artigo poderão ser replicados em outras áreas de estudo cujo fogo é visto como um evento conflitante.

\section{Conclusões}

Mesmo após 40 anos da criação do PNSC, ainda ocorrem atividades conflitantes que ameaçam o equilíbrio desta UC, e as queimadas estão entre elas. A aplicação do teste $K S$ comprovou que há de relação espacial entre a propagação de queimadas no parque e as variáveis geoambientais hipsometria, declividade, índice de convexidade da superfície, efeito do vento, índice de vegetação, densidade de vias e densidade de drenagem. $O$ teste possibilitou também atribuir pesos a estas variáveis, que foram aplicados na modelagem do perigo de propagação de queimadas.

O modelo revelou que, interior dos Chapadões da Canastra e da Babilônia, são as áreas de maior perigo de propagação de queimadas, especialmente, por estarem associados a coberturas vegetais de baixa biomassa, altitudes elevadas, alto efeito do vento e baixa densidade de vias. As depressões intermontanas, áreas rebaixadas que individualizam os Chapadões, estão associadas a médios valores de perigo de propagação. A noroeste e a centro-norte da ZA, o perigo varia entre médio, nas médias e altas encostas, e baixo, nos fundos de vale. Por outro lado, ao sul e a leste da ZA, o perigo predominante é baixo.

As queimadas no Chapadão da Babilônia são mais recorrentes que no Chapadão da Canastra, apesar do perigo de propagação de ser semelhante entre estas duas zonas. Isto ocorre em função das restrições do uso do solo no Chapadão da Canastra, que reduz o risco de ignição, e também pela atuação institucional, que faz com que haja maior controle do fogo nesta zona. Pode-se afirmar, então, que a regularização fundiária do Chapadão da Babilônia é de fundamental importância no controle das queimadas, e também é necessário maior apoio financeiro e profissional para o parque, para que se possam realizar ações de combate e prevenção nos dois Chapadões ao mesmo tempo.

A metodologia criada neste artigo mostrou-se eficiente, e sua confiabilidade e precisão foram comprovadas. Os resultados desta pesquisa poderão ser utilizados no manejo do fogo no PNSC, já que os gestores ainda não possuem um produto cartográfico que destaque as áreas potencialmente mais propensas à propagação de queimadas, podendo assim minimizar os impactos negativos em locais de alta recorrência e de perigo de propagação.

\section{Referências}

AJIN, R. S.; LOGHIN, A. M.; KARKI, A.; VINOD, P. G.; JACOB, M. K. Delineation of forest fire risk zones in Thenmala forest division, Kollam, Kerala, India: a study using geospatial tools. J. Wetlands Biodiversity, v. 6, p. 175-184, 2016.

ALLGÖWER, B.; CARLSON, J. D.; WAGTENDONK, J. W. Introduction to fire danger rating and remote sensing: will remote sensing enhance wildland fire danger rating? In.: CHUVIECO, E (ed.). Wild fire danger estimation and mapping: the role of remote sensing data. Danvers, EUA: World Scientific Publishing Co. Pte. Ltd., 2003. p. $1-19$

BÖHER, J.; ANTONIC, O. Land Surface Parameters Specific to Topo-Climatology. HENGL, T.; REUTER, H. I. In.: Geomorphometry: Concepts, software, applications. Oxford: Elsevier, 2009.

CARVALHO, E. V.; BATISTA, A. C.; COELHO, M. C. B.; NEVES, C. O. M.; SANTOS, G. R.; GIONGO, M. Caracterização de áreas queimadas no estado do Tocantins no ano de 2014. Floresta, v. 47, n. 3, p. 269278, 2017.

COURA, P. H. F.; SOUZA, G. M.; FERNANDES, M. C. Mapeamento Geoecológico da Susceptibilidade à Ocorrência de Incêndios no Maciço da Pedra Branca, Município do Rio de Janeiro. Anuário do Instituto de Geociências - UFRJ, v. 32, n. 2, p. 14-25, 2009.

CHUVIECO, E.; AGUADO, L.; YEBRA, M.; NIETO, H.; SALAS, J.; MARTÍN, M. P.; VILAR, L.; MARTINÉZ, J.; MARTÍN, S.; IBARRA, P.; RIVA, J. de la; BAEZA, J.; RODRÍGUEZ, F.; MOLINA, J. R.; 
HERRERA, M. A.; ZAMORA, R. Development of a framework for fire risk assessment using remote sensing and geographic information system technologies. Ecological Modelling, v. 221, p. 46-58, 2010.

CONTI, J. B.; FURLAN, S. A. Geoecologia: o clima, os solos e a biota. In.: ROSS, J. L. S. (org.) Geografia do Brasil. $6^{a}$ ed. São Paulo: Edusp, 2011.

COSTA-MILANEZ, C. B.; RIBEIRO, F;. F.; CASTRO, P. T. A.; MAJER, J. D.; RIBEIRO, S. P. Effect of Fire on Ant Assemblages in Brazilian Cerrado in Areas containing Vereda Wetlands. Sociobiology, v. 62, n. 4, p. 494-505, 2015.

CUI, W.; PERERA, A. H. What do we know about forest fire size distribution, and why is this knowledge useful for forest management? International Journal of Wildland Fire, v. 17, p, 234-244, 2008.

DURIGAN, G.; RATTER, J. A. The need for a consistent fire policy for Cerrado conservation. Journal of Applied Ecology, v. 53, p. 11-15, 2016.

ESKANDARI, S.; CHUVIECO, E. Fire danger assessment in Iran based on geospatial information. International Journal of Applied Earth Observation and Geoinformation, v. 42, p. 57-64, 2015.

FERREIRA, M. C. Iniciação à análise geoespacial: teoria, técnicas e exemplos para geoprocessamento. Rio Claro: Ed. Unesp, 2014.

FRANKE, J.; BARRADAS, A. C. S.; BORGES, M. A.; COSTA, M; M.; DIAS, P. A.; HOFFMANN, A. A.; OROZCO FILHO, J. C.; MELCHIORI, A. E.; SIEGERT, F. Fuel load mapping in the Brazilian Cerrado in support of integrated fire management. Remote Sensing of Environment, v. 217, p. 221-232, 2018.

GAGNON, P. R.; PASSMORE, H. A; SLOCUM, M.; MYERS, J. A.; HASRMS, K. E.; PLATT, W. J.; PAINE, C. E. T. Fuels and fires influence vegetation via above- and belowground pathways in a highdiversity plant community. Journal of Ecology, v. 103, p. 1009-1019, 2015.

GOMES, L.; MIRANDA, H. S.; BUSTAMANTE, M. M. C. How can we advance the knowledge on the behavior and effects of fire in the Cerrado biome? Forest Ecology and Management, v. 417, p. 281-290, 2018.

IWAHASHI, J.; RICHARD, P. Automated classifications of topography from DEMs by an unsupervised nested-means algorithm and a three-part geometric signature. Geomorphology, v. 86, p. 409-440, 2007.

MAGALHÃES, S. R.; LIMA, G. S.; RIBEIRO, G. A. Avaliação dos incêndios florestais ocorridos no Parque Nacional da Serra da Canastra - Minas Gerais. Cerne, v. 18, n. 1, p. 135-141, 2012.

MESSIAS, C. G.; FERREIRA, M. C. Mapeamento têmporo-espacial das queimadas no Parque Nacional da Serra da Canastra (MG) e suas relações com as zonas de planejamento. In: PEREZ FILHO, A.; AMORIM, R. R. Os desafios da Geografia Física na fronteira do conhecimento. Campinas: UNICAMP, 2017.

MMA; IBAMA. Plano de Manejo: Parque Nacional da Serra da Canastra. Brasília: MMA, 2005.

MMA; ICMBIO; PNSC. Processo 02070.000978/2018-19 / SEI 2668224. O parque Nacional da Serra da Canastra: breves considerações históricas, logísticas e gerenciais. São Roque de Minas: SEI, 2018.

POLDONI, L.; GANIS, P.; VIDALI, M.; ALTOBELLI, A.; BALDER, F.; CANTELE, S. Inclusion of phytosociological data in an index of vegetation fire danger: application and mapping on the Karst area around Trieste (Italy). Official Journal of the Societa Botanica Italiana, v. 152, n. 4; p. 810-817, 2017.

RISSI, M. N.; BAEZA, M. J.; GORGONE,-BARBOSA, E.; ZUPO, T.; FIDELIS, A. Does season affect fire behaviour in the Cerrado? International Journal of Wildland Fire, v. 26, 427-433, 2017.

STEVENS, J. T.; BECKAGE, B. Fire feedbacks facilitate invasion of pine savannas by Brazilian pepper (Schinus terebinthifolius). New Phytologist, v. 184, p. 365-375, 2009.

TAYLOR, P. J. Inferential statistic. In: TAYLOR, P. J. Quantitative methods in geography. Boston, Houghton Mifflin Co., p. 102-123, 1977.

TORRES, F. T. P. Relação entre fatores climáticos e ocorrência de incêndios florestais na cidade de Juiz de Fora (MG). Caminhos de Geografia, v. 7, n. 18, p. 162-171, 2006. 